\title{
A Novel Terpolymer as Fluid Loss Additive for Oil Well Cement
}

\author{
Ming Li, ${ }^{1,2}$ Dongbo Xie, ${ }^{1}$ Zihan Guo, ${ }^{1}$ Ya Lu, ${ }^{1}$ and Xiaoyang Guo ${ }^{3}$ \\ ${ }^{1}$ School of Material Science and Engineering, Southwest Petroleum University, Chengdu 610500, China \\ ${ }^{2}$ State Key Laboratory of Vanadium and Titanium Resources Comprehensive Utilization, Panzhihua, Sichuan 617000, China \\ ${ }^{3}$ State Key Laboratory of Oil and Gas Reservoir Geology and Exploration, Southwest Petroleum University, Chengdu 610500, China
}

Correspondence should be addressed to Xiaoyang Guo; 851728419@qq.com

Received 14 December 2016; Accepted 8 February 2017; Published 12 March 2017

Academic Editor: Bernabé L. Rivas

Copyright (C) 2017 Ming Li et al. This is an open access article distributed under the Creative Commons Attribution License, which permits unrestricted use, distribution, and reproduction in any medium, provided the original work is properly cited.

\begin{abstract}
A terpolymer comprised of sodium styrene sulfonate (SSS), fumaric acid (FA), and acrylamide (AM) was synthesized by aqueous free radical copolymerization and evaluated as fluid loss additive for oil well cement. The chemical structure and performance of the terpolymer were characterized by Fourier transform infrared (FTIR) spectroscopy and thermal gravimetric analysis (TGA); the molecular weight and its distribution were determined by gel permeation chromatography (GPC). The optimum reaction conditions of polymerization were obtained: a reaction temperature of $50^{\circ} \mathrm{C}$, a mass ratio of SSS/FA/AM $4: 2: 14$, initiator $0.1 \%$, and reaction time of $4 \mathrm{~h}$; characterization indicated that the SSS/FA/AM had a certain molecular weight and excellent temperatureresistant and salt-resistant properties. The results show that SSS/FA/AM has a good fluid loss performance, in which the API fluid loss of the oil cement slurry could be controlled within $100 \mathrm{~mL}$ at $160^{\circ} \mathrm{C}$. In addition, it had little effect on the cement compressive strength. The results of scanning electron microscopy (SEM) of the filter cake showed that SSS/FA/AM could be adsorbed on the surface of the cement particles and produce a hydrated layer to prevent fluid loss from the oil well cement.
\end{abstract}

\section{Introduction}

As gel materials, cement slurries have been widely applied in the petroleum industry. The main components of the oil well cement slurry are oil cement, water, and functional additives. The fluid loss additives, which are one of the three main additives on the oil cement slurry, can effectively reduce the fluid loss of oil cement slurry in the field condition and can also increase the viscosity and improve the stability of oil cement slurry $[1,2]$. However, when the traditional fluid loss additives are applied in practice, the resulting oil cement slurry often has poor properties: high filtration, instability, and brittleness, especially in high temperature or high salt environments [3]. In the traditional oil well industry $[4,5], 2$-acrylamide-2-methylpropanesulfonic acid (AMPS), with its superior performance, has been widely used in cement admixtures. However, the sulfonic group connected by amide bonds are easily hydrolysis (Figure 1) in alkaline solutions at high temperature and form low molecular weight organic sulfonates. As a result, the organic sulfonates influence the dispersion of the cement slurry. Carboxylic acid formed by the hydrolysis also prolongs the setting time of the cement.

Our objective in the research described here was to use new monomers to synthesize a novel fluid loss additive. In order to ensure that it has a superior performance to control the fluid loss of the oil cement slurry, the macromolecular polymers should have rigid radical, strong absorption groups to the oil cement particles and superior thickening properties $[6,7]$. The sodium styrene sulfonate (SSS) not only contains a benzene ring $\left(\mathrm{C}_{6} \mathrm{H}_{5}{ }^{-}\right)$which provides excellent temperature resistance but also has a sulfo-group $\left(-\mathrm{SO}_{3}{ }^{-}\right)$which is insensitive to outside cations, resulting in the terpolymer being hydrophilic and salt tolerant. In addition, the acrylamide (AM), including the amide $\left(-\mathrm{CONH}_{2}\right)$ group, was added to the terpolymer to make sure the additive had an excellent stabilization and thickening property [8-10]. As an improved fluid loss additive, a monomer with an adsorbing group for the cement particles can ensure the other functional groups could play their role, that is, the carboxylic group $(-\mathrm{COOH})$ was introduced by the fumaric acid (FA). Thus, in this work, a fluid loss additive with high temperature and salt 


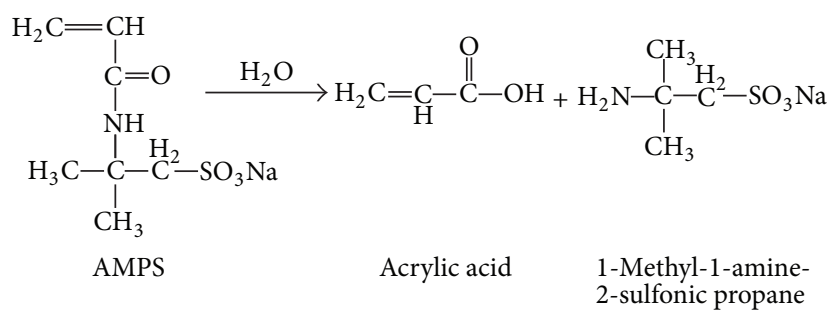

FIgURE 1: The hydrolysis process of AMPS.

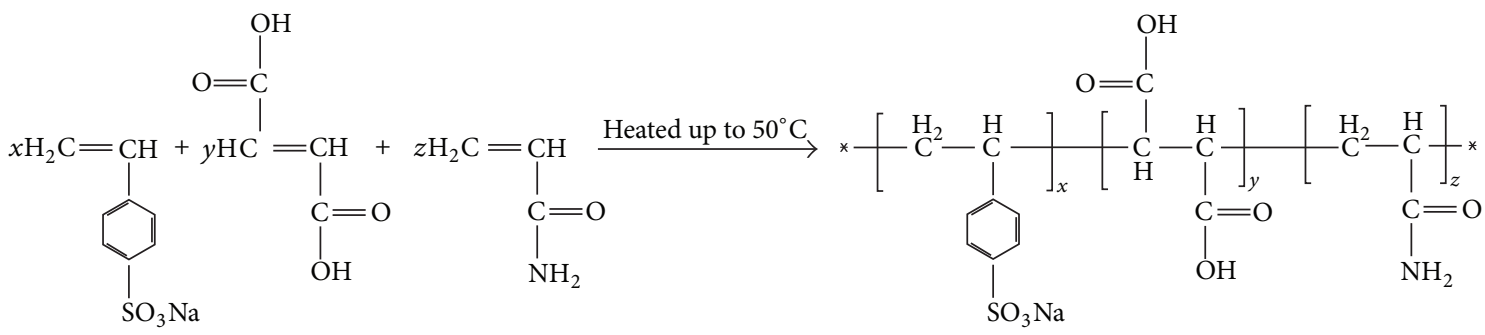

SSS

FA

$\mathrm{AM}$

SSS/FA/AM

FIGURE 2: Schematic diagram of the terpolymerization.

resistance was synthesized by the polymerization of SSS, AM, and FA.

\section{Experimental}

2.1. Materials. SSS, FA, and AM were purchased from Shanghai Aladdin Industrial Corp. (Shanghai, China). Potassium persulfate and sodium hydroxide were supplied from Chengdu Kelong Chemical Reagent Factory (Sichuan China). Class $\mathrm{G}$ oil well cement which is high sulfate-resistant grade cement was obtained from Jiahua Enterprises Corp. (Sichuan China); it corresponded to American Petroleum Institute (API) Specification 10A.

\subsection{Methods}

2.2.1. Synthesis of SSS/FA/AM. SSS $(20.0 \pm 0.5 \mathrm{mg})$, FA ( 10.0 $\pm 0.5 \mathrm{mg})$, and $\mathrm{AM}(7.0 \pm 0.5 \mathrm{mg})$ were placed in different beakers and used a magnetic stirrer to dissolve in deionized water (the total ratio of solid to liquid in each beaker was $8 \%$ ). The $\mathrm{PH}$ values of all solutions were adjusted to the appropriate value $(\mathrm{pH}=7)$ with sodium hydroxide solution. The FA and SSS solutions were then mixed together and added to a threenecked flask. Finally, the AM solution was slowly added to the reactor; at the same time, $0.1 \%$ wt initiator was also slowly added to the system. Nitrogen gas was pumped slowly into the system for $30 \mathrm{~min}$. The reaction temperature was stabilized at $50^{\circ} \mathrm{C}$. After reaction, the product was extracted with ethanol three times, and then the granular product was stored in a drying oven $\left(60^{\circ} \mathrm{C}\right)$. The reaction equation is shown in Figure 2.

2.2.2. Basic Characterization of SSS/FA/AM. The investigation of the chemical structure of SSS/FA/AM was conducted using Fourier transform infrared spectrometer (WQF520, Beijing Rayleigh Analytical Instrument Corp., China). The sample was mixed with $\mathrm{KBr}$ and then was compressed into flake. The scan range was from 4000 to $500 \mathrm{~cm}^{-1}$.

The molecular weight and molecular weight distribution were measured by gel permeation chromatography (GPC) (Alliance e2695, Waters Corp., USA). The SSS/FA/AM was dissolved in distilled water $(8 \mathrm{mg} / \mathrm{mL})$ by stirring at $25^{\circ} \mathrm{C}$ for 90 min before testing.

The temperature resistance of the sample was measured by thermogravimetric analysis (TGA/SDTA85, Mettler Toledo, Switzerland). The testing temperature covered the range of 25 to $500^{\circ} \mathrm{C}$ at a scan rate of $10^{\circ} \mathrm{C} / \mathrm{min}$.

2.2.3. The Ability of SSS/FA/AM to Control Fluid Loss for the Oil Cement Slurry. Preparation and fluid loss testing of the cement slurry were done according to API Recommended Practice for testing oil well cements 10B (API RP 10B) [11]. All of the testing results were determined using a high temperature and high pressure filtration instrument (OWC9510, Applied Technology Research Institute of Shenyang Aerospace University). The terpolymer (1\%, $2 \%$, and $3 \%$, by weight of cement) was mixed with the API Class $\mathrm{G}$ oil cement and water, and the water/cement ratio was 0.44 . The cement slurries were mixed at a high speed mixer $(4000 \mathrm{r} / \mathrm{min} \pm 200 \mathrm{r} / \mathrm{min}$ for $15 \mathrm{~s}$, then $12000 \mathrm{r} / \mathrm{min}$ $\pm 500 \mathrm{r} / \mathrm{min}$ for $35 \pm 1 \mathrm{~s})$. The slurries were placed into the filtration instrument to test the fluid loss using testing temperatures of $60,90,100,120,140$, and $160^{\circ} \mathrm{C}$, at a $6.9 \mathrm{MPa}$ gas pressure for $30 \mathrm{~min}$. In order to verify the salt tolerance of the terpolymer, saturated brine and half saturated brine, in place of the water, were added to the cement slurries to test the fluid loss in the same testing environment. After the fluid loss test, the filter cake of the sample was covered with a layer of 


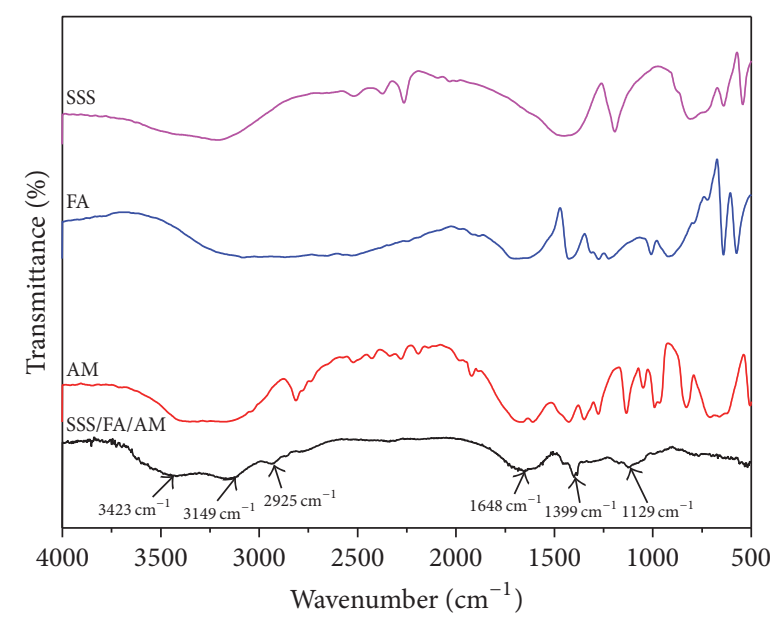

FIGURE 3: FTIR spectra of SSS, FA, AM, and SSS/FA/AM.

gold and imaged in a scanning electron microscope (Quanta $450, \mathrm{FEI}$ Co, USA) to analyze the microstructure.

\subsubsection{Effect of SSS/FA/AM on the Oil Cement's General} Properties. Different proportions of the terpolymer (1\%, 2\%, and $3 \%$, by weight of cement) were mixed with the oil cement, and the water/cement ratio was also 0.44 . With a ration of $4000 \mathrm{r} / \mathrm{min} \pm 200 \mathrm{r} / \mathrm{min}$ for $15 \mathrm{~s}$ and then $12000 \mathrm{r} / \mathrm{min} \pm$ $500 \mathrm{r} / \mathrm{min}$ for $35 \pm 1 \mathrm{~s}$, the oil cement slurry was fulfilled in a cubic model $\left(4 \times 4 \times 4 \mathrm{~cm}^{3}\right)$ to test the compressive strength. The curing temperatures were set at 90,120 , and $140^{\circ} \mathrm{C}$ and the curing time at $24 \mathrm{~h}$ and $48 \mathrm{~h}$.

\section{Results and Discussion}

3.1. Chemical Structure and Molecular Weight of SSS/FA/AM. After being purified and dried, the chemical structure of the terpolymer was analyzed by FTIR.

The Fourier transform infrared (FTIR) spectrometer spectra of SSS, FA, AM, and the terpolymer are shown in Figure 3. The band at $3423 \mathrm{~cm}^{-1}$ is an $\mathrm{O}-\mathrm{H}$ stretching vibrations absorption in the carboxylic acid groups of FA while $3150 \mathrm{~cm}^{-1}$ is assigned to the stretching vibration of $\mathrm{N}-\mathrm{H}$ in the amide group in AM and $2925 \mathrm{~cm}^{-1}$ is the characteristic absorption signal of methyl and methylene groups. The absorption peaks observed at $1648 \mathrm{~cm}^{-1}$ and $1130 \mathrm{~cm}^{-1}$ are the characteristic absorption bands of $\mathrm{C}=\mathrm{O}$ and $\mathrm{C}-\mathrm{O}$ in the carboxyl groups introduced by FA and AM. The characteristic peak at $1076 \mathrm{~cm}^{-1}$ corresponds to the symmetric stretching vibrations of $\mathrm{S}=\mathrm{O}$ in the sulfonate group introduced by SSS, but the characteristic band at $837 \mathrm{~cm}^{-1}$ is the stretching vibrations absorption signal corresponding to para-substituted benzene structure. From $1630 \mathrm{~cm}^{-1}$ to $1645 \mathrm{~cm}^{-1}$, there was no characteristic absorption peak of vinyl $\left(-\mathrm{CH}=\mathrm{CH}_{2}\right)$, and the results demonstrate that there were no monomer residues in the analysis samples. According to our analysis of the FTIR spectrum, we can conclude that the target copolymer was obtained (Figure 2).

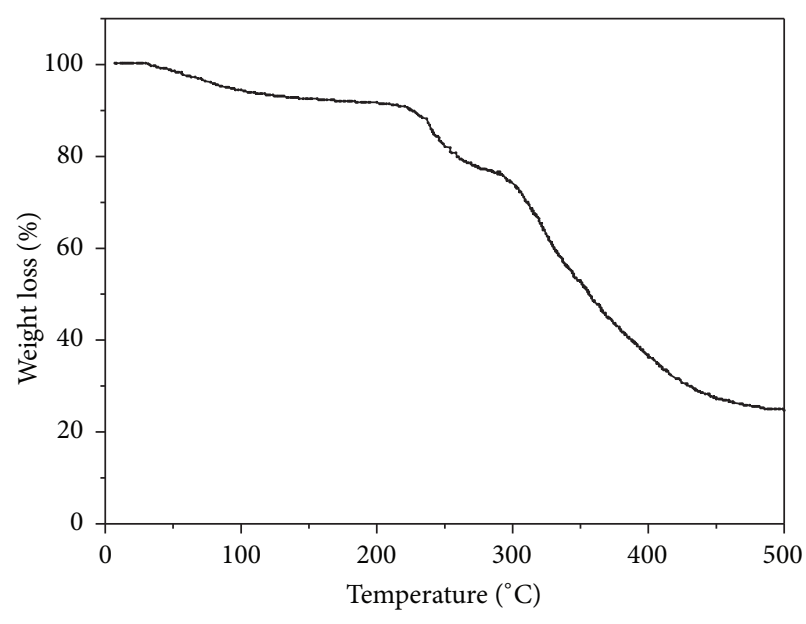

FIGURE 4: TGA of SSS/FA/AM.

The molecular weight and its distribution of the terpolymer were measured by gel permeation chromatography (GPC). The results showed that the number-average molecular weight was $3.7 \times 10^{5}$, and the weight-average molecular weight was $5.5 \times 10^{5}$. The molecular weight distribution was 1.48 which is a relatively modest value. It is well known that the terpolymer molecular weight and its particle size in solvent have a close relationship. Therefore, molecular weights and its distribution above a certain range can plug the irregular cracks between cement particles to reduce water loss through an indirect route [12].

3.2. Simultaneous Thermogravimetric and Differential Thermal Analysis of the Terpolymer. The TGA curve of $25-500^{\circ} \mathrm{C}$ of the terpolymer is suggested to Figure 4 . In the curve of the terpolymer, the weight loss from $25^{\circ} \mathrm{C}$ to $130^{\circ} \mathrm{C}$ might be caused by volatilization of free water and decomposition of small molecular weight impurities. When the temperature rose to $250^{\circ} \mathrm{C}$, the curve shows that the terpolymer had about $10 \%$ total weight loss. We think that the reason for this phenomenon may be degradation of side groups on the molecular chains. Ultimately, when the temperature was above $330^{\circ} \mathrm{C}$, the sample had a large mass loss, with breakage of the main chain of the terpolymer being a possible reason. At this temperature, the structure of the terpolymer was destroyed and it cannot effectively control fluid loss of the cement slurry.

3.3. Fluid Loss Control Performance. The fluid loss of the oil cement slurry with varying contents of the SSS/FA/AM was tested, and the temperature range was between 60 and $160^{\circ} \mathrm{C}$. The results are shown in Figure 5. For the fluid loss additive in field applications, $90^{\circ} \mathrm{C}$ is one performance dividing line and $120^{\circ} \mathrm{C}$ is another performance dividing line. Thus, temperatures from 60 to $160^{\circ} \mathrm{C}$ were used for the tests. It can be seen that the fluid loss decreased gradually with the increase of terpolymer SSS/FA/AM dosage. In addition, at $90^{\circ} \mathrm{C}$ or less, the SSS/FA/AM maintained an excellent performance about fluid loss, and the fluid loss of cement 


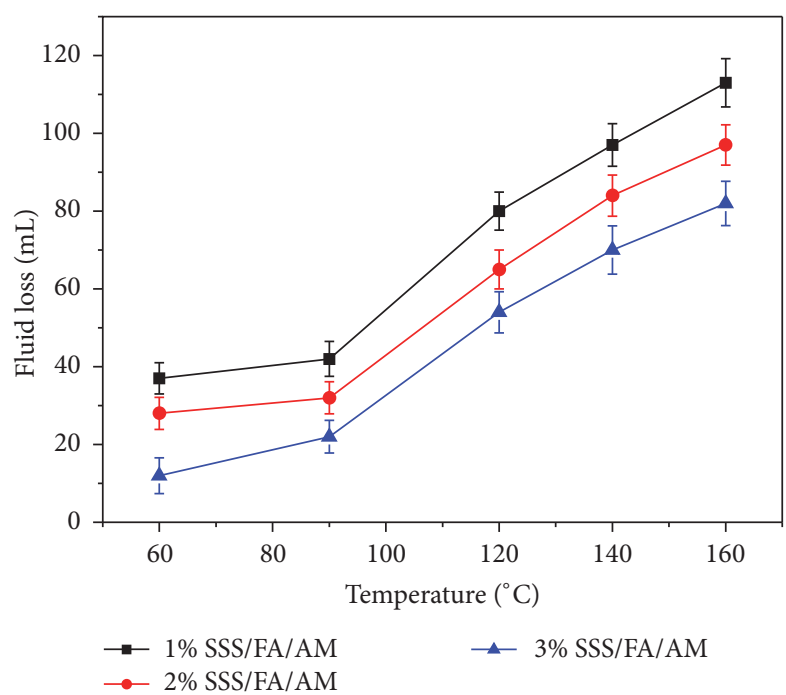

FIgURE 5: Fluid loss of terpolymer at different temperatures.

slurry is below $40 \mathrm{~mL}$. When in temperatures higher than $90^{\circ} \mathrm{C}$, the terpolymer also showed good performance, and the fluid loss of cement slurry is below $100 \mathrm{~mL}$. On the other hand, the fluid loss decreased with the increase of terpolymer dosage. Thus, it was proved that the terpolymer, SSS/FA/AM, could have a significant potential for controlling fluid loss.

3.4. Evaluation of Salt Toleration. It was difficult to control the fluid loss of the cement slurries in the saline fields, which are strong electrolytes. Because the radius of $\mathrm{Na}^{+}$is small, it is easy to enter between the groups of the terpolymer molecules, leading to polymer chains shrinkage; due to shrinkage of the polymer chains, it makes the polymer chains merely difficult to be adsorbed on the surface of the cement particles, resulting in increased fluid loss [13]. As is known [12], the $-\mathrm{SO}_{3}$ in the SSS is not sensitive to salt and the presence of benzene increased molecular chain rigidity, with, as a result, SSS having good resistance to temperature and salt. Therefore, it is necessary to ensure that the terpolymer has outstanding properties of salt tolerance.

From Figures $6-8$, the test temperatures were set at 90 , 120 , and $140^{\circ} \mathrm{C}$, respectively. The fluid loss of brine cement slurry obviously reduced with the increase of terpolymer dosage. When the dosage of terpolymer was $3 \% \mathrm{wt}$, the fluid loss could be controlled less than $100 \mathrm{~mL}$. The result indicates that the terpolymer has excellent salt tolerance, and we attribute this to the presence of monomers with the sulfonic acid groups.

3.5. Evaluation of General Properties of Oil Cement. As a fluid loss additive of oil well cement with good performance, it should be satisfied with two conditions: having no effect on the strength development of cement paste and having a positive influence on the sedimentation stability of the cement slurry. It is accepted that the critical temperature
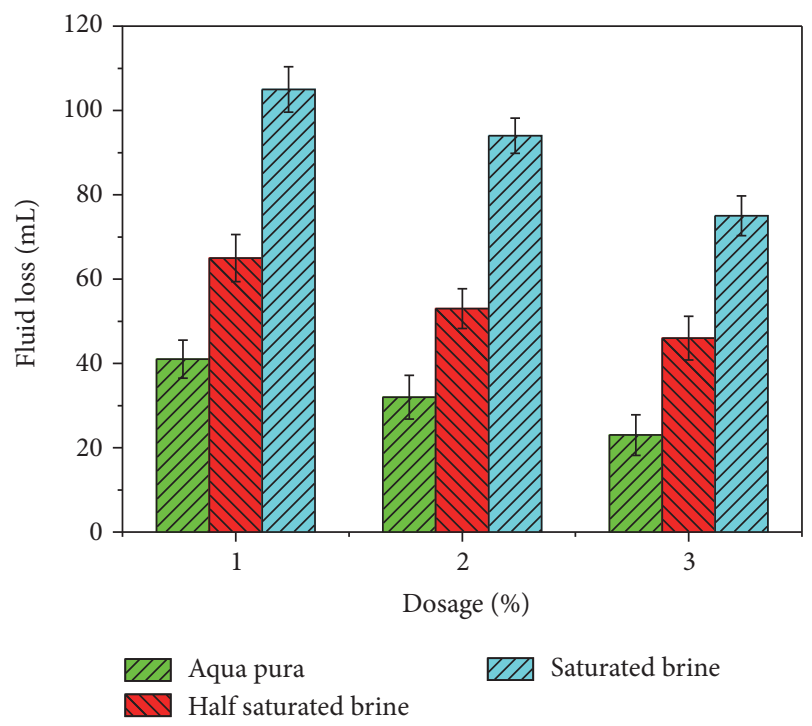

Figure 6: Performance evaluation of salt resistance at $90^{\circ} \mathrm{C}$.

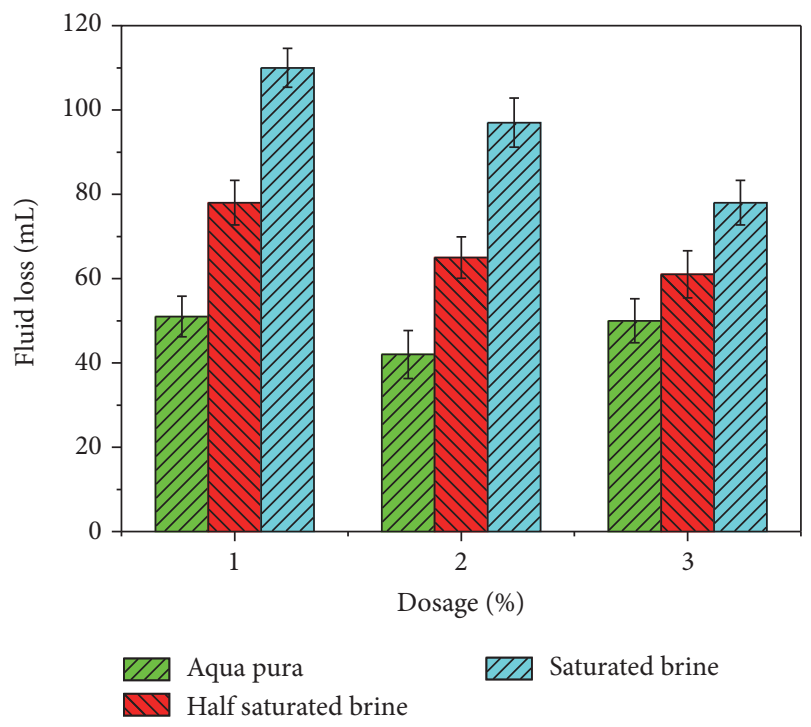

FIGURE 7: Performance evaluation of salt resistance at $120^{\circ} \mathrm{C}$.

for high temperature strength attenuation of oil cement is $110^{\circ} \mathrm{C}$ [14]. In addition, for general engineering applications, it has been concluded that the compressive strength of cement paste should be achieved to be $3.5 \mathrm{MPa}$ or more, with the goal of supporting the oil well sleeve axial load.

From Table 1, we can conclude that there was a little effect on the compressive strength of the cement paste with variations in the amounts of SSS/FA/AM and dispersant added. As the temperature was increased, the development of the compressive strength of the cement paste was accelerated in $24 \mathrm{~h}$, but the recession of the compressive strength of the cement paste was accelerated too in $48 \mathrm{~h}$. The values of fluid loss indicate full compliance with the basic requirements of an oil field construction site for the compressive strength of the cement paste, with construction sand and other 
TABLE 1: Compressive strength of oil cement with SSS/FA/AM under different temperatures.

\begin{tabular}{|c|c|c|c|c|}
\hline \multirow{2}{*}{ Curing temperature $\left({ }^{\circ} \mathrm{C}\right)$} & \multirow{2}{*}{$\begin{array}{c}\text { Dosage of SSS/FA/AM (wt\%, } \\
\text { BWOC) }\end{array}$} & \multirow{2}{*}{ Dispersant (wt\%, BWOC) } & \multicolumn{2}{|c|}{ Compressive strength (MPa) } \\
\hline & & & $24 \mathrm{~h}$ & $48 \mathrm{~h}$ \\
\hline \multirow{3}{*}{90} & 1 & 0 & 22.5 & 25.7 \\
\hline & 2 & 0.3 & 20.4 & 21.1 \\
\hline & 3 & 0.3 & 19.1 & 21.0 \\
\hline \multirow{3}{*}{120} & 1 & 0 & 26.8 & 24.7 \\
\hline & 2 & 0.3 & 23.7 & 20.9 \\
\hline & 3 & 0.3 & 23.2 & 19.5 \\
\hline \multirow{3}{*}{140} & 1 & 0 & 28.5 & 23.1 \\
\hline & 2 & 0.3 & 25.3 & 19.6 \\
\hline & 3 & 0.3 & 24.9 & 17.3 \\
\hline
\end{tabular}

Note: BWOC means "by weight of cement." The dispersant was SXY-2 (Chengdu Chuanfeng Chemical Engineering Co., Ltd., Sichuan, China), that is, a condensation copolymer of acetone and formaldehyde. The chemical structure is exhibited in Figure 9.

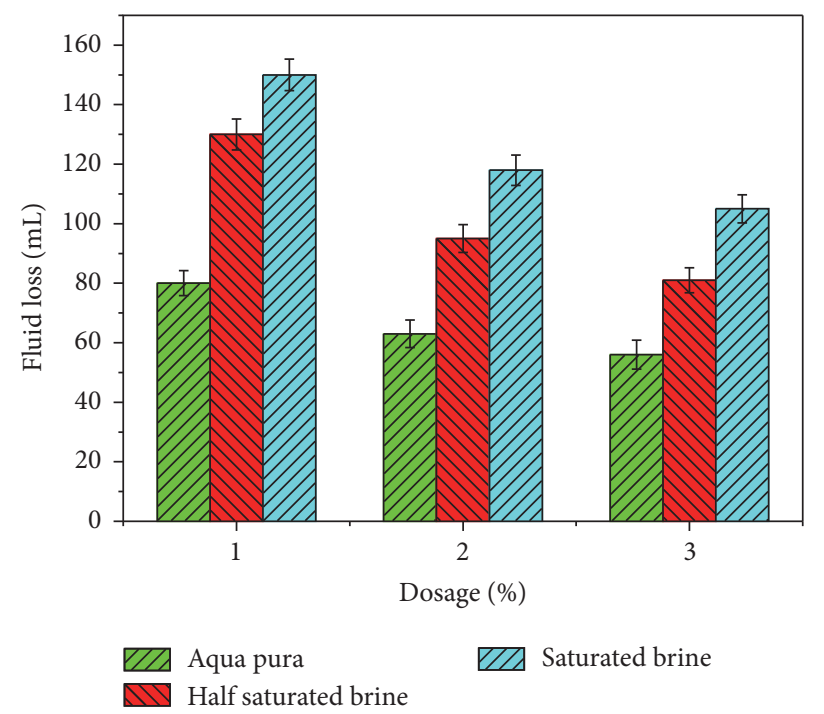

Figure 8: Performance evaluation of salt resistance at $140^{\circ} \mathrm{C}$.<smiles>[X]C(C)(C)CC(C)=O</smiles>

FIgURE 9: Chemical structure of SXY-2.

methods being often added to improve the cement strength [15].

3.6. SEM Analysis of Filter Cake. In oil cement slurry, the oil cement has a certain particle size distribution, which can lead to the formation of water channeling and promote the flow of water. A large amount of water loss will occur during the formation of the filter cake, and the water loss rate depends on the nature of the filter cake. Excellent fluid loss additives can effectively cause the cement particles to clog the gaps, forming a dense cake and reducing water loss. To explore the microstructure of the filter cake, it was observed by SEM.
The SEM images of filter cake are shown in Figure 10, after fluid loss at $120^{\circ} \mathrm{C}, 6.9 \mathrm{MPa}, 30 \mathrm{~min}$. (a) and (b) had $3 \mathrm{wt} \%$ fluid loss additive, and (c) and (d) had $1 \mathrm{wt} \%$ fluid loss additive, but (e), (f), and (g) were without fluid loss additive. It can be seen that the SEM images of filter cake $(\mathrm{e}, \mathrm{f}, \mathrm{g})$ without fluid loss additive were different from the others. There were many small gaps in the images (e), (f), and (g). All of these gaps became channels for free water, which was the reason for the high fluid loss. The results showed that, with the increase of contents of fluid loss additives in cement slurry, the microstructure of filter cake becomes denser. 


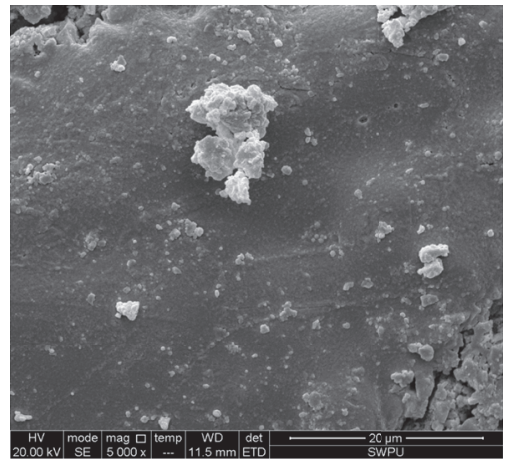

(a)

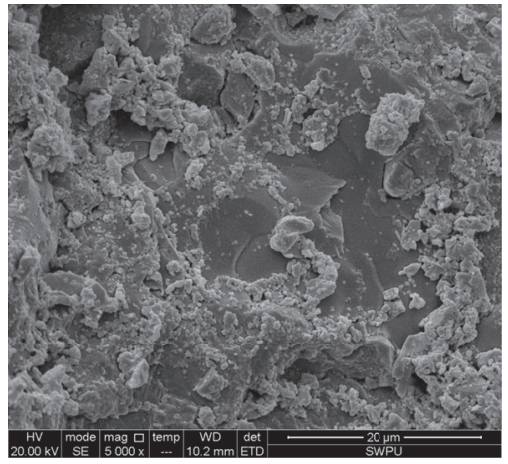

(d)

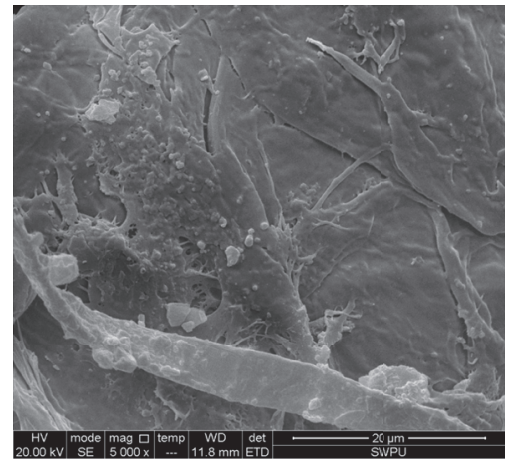

(b)

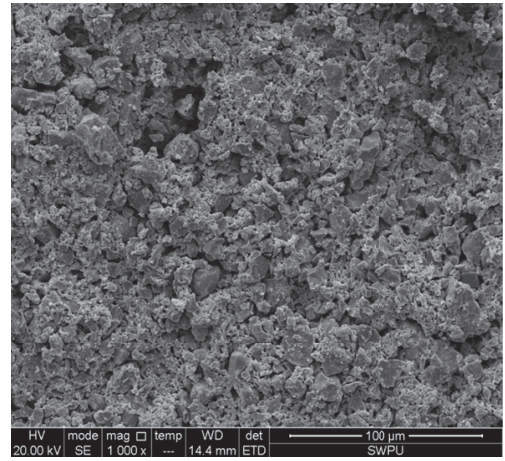

(e)

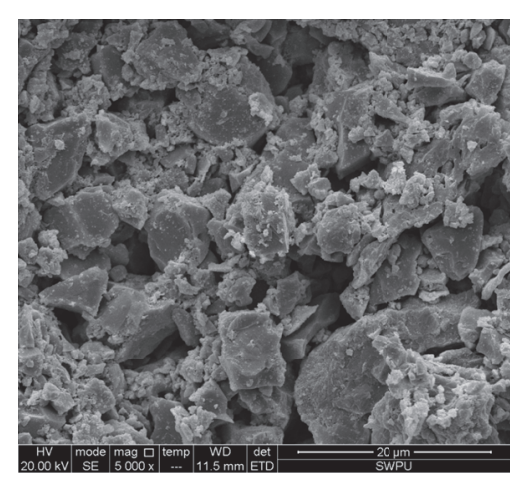

(g)

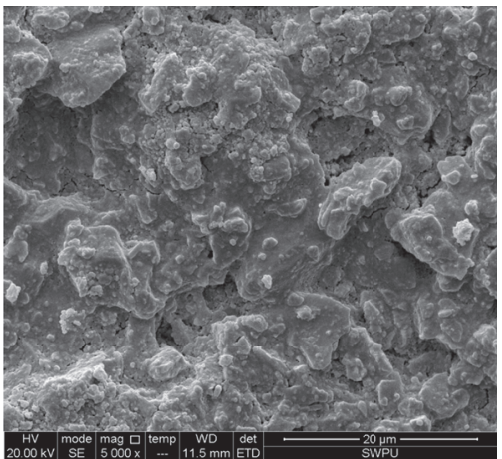

(c)

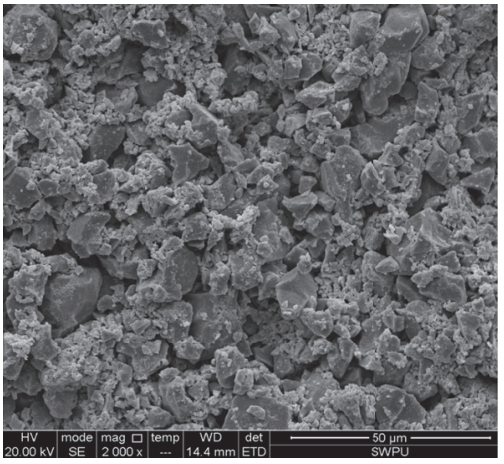

(f)

FIGURE 10: SEM images of filter cake of the cement slurries after the fluid loss tests (a and b) with 3\% wt SSS/FA/AM, (c and d) with 1\% wt SSS/FA/AM, and (e, f, and g) without SSS/FA/AM additives.

The interaction between cement particles and the terpolymer in oil cement slurry is shown in Figure 11. We can conclude that the effect of fluid loss additive on the cement slurries was as follows. First, the terpolymer of SSS/FA/AM was wrapped on the cement particles and then produced a hydrated layer to prevent fluid loss in the cement slurry. Second, the long chains of the terpolymer of SSS/FA/AM twine around each other to form clusters in solution, which contributes to reducing the liquidity of the filtrate and increases the filtration resistance of the filter cake. As a result of pores in the filter cake being effectively blocked, the fluid loss of cement slurries was controlled.

\section{Conclusions}

A novel fluid loss additive, the terpolymer of SSS/FA/AM, was synthesized by aqueous free radical copolymerization. Based on FTIR analysis, the structure of the terpolymer was consistent with the designed one. The number-average molar mass of the polymer was $3.7 \times 10^{5}$, and the weightaverage molecular weight was $5.5 \times 10^{5}$. TGA showed that the terpolymer began to decompose at $250^{\circ} \mathrm{C}$. The fluid loss test showed that the terpolymer of SSS/FA/AM had a good performance of salt tolerance and temperature tolerance in the range of 60 to $160^{\circ} \mathrm{C}$. The compressive strength test 


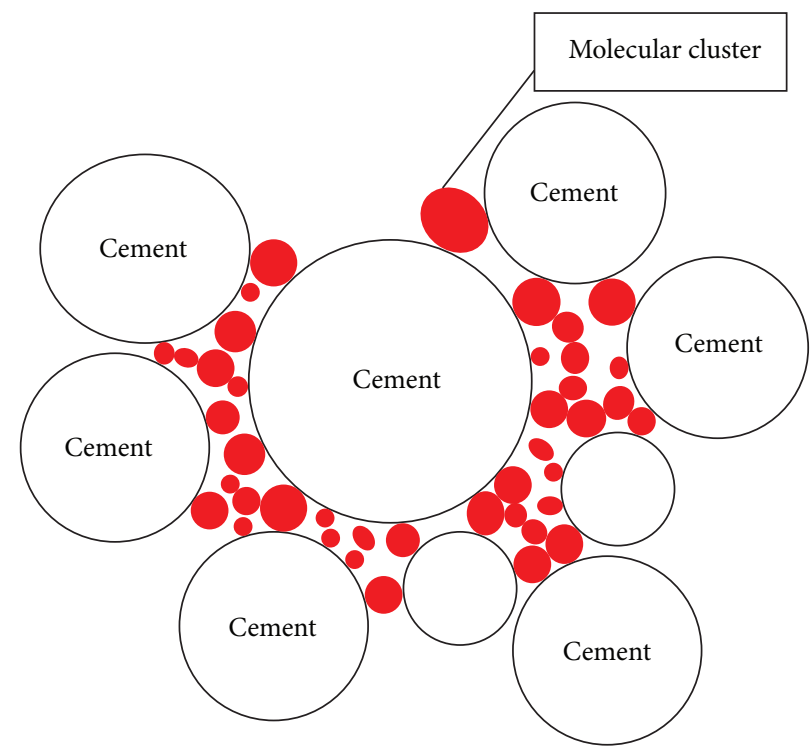

FIGURE 11: Interaction between cement particles and SSS/FA/AM in oil cement slurry.

showed that SSS/FA/AM had only a small effect on the development of cement paste strength. At the same time, the SEM analysis showed that the structure of filter cake with the terpolymer being denser than the structure of filter cake without the terpolymer resulting in the gaps between the cement particles being filled with the terpolymer. Eventually, the fluid loss of cement slurry was prevented.

\section{Competing Interests}

The authors declare that they have no competing interests.

\section{Acknowledgments}

The authors would like to acknowledge the cofinancial support by the National Science and Technology Major Project (nos. 2016ZX05020004-008 and 2016ZX05052) and CNPC Science and Technology Project (2016A-3903) for the financial support.

\section{References}

[1] J. F. Baret, "Why cement fluid loss additives are necessary," Clinical Neurology, vol. 35, no. 12, pp. 1422-1424, 1988.

[2] A. Savoly, J. L. Villa, C. M. Garvey, and A. L. Resnick, "Fluid loss agents for oil well cementing composition," US, US4674574. 1987.

[3] K. K. Ganguli, "High temperature fluid loss additive for cement slurry and method of cementing," US, US5116421. 1992.

[4] J. L. Zou, J. S. Qu, Y. S. Xu, Y. H. Gao, and H. J. Zhu, "Developments of retarders for oil well cementing compositions," Oilfield Chemistry.
[5] J.-L. Zou, J.-S. Qu, Y.-S. Xu, and D.-H. Wu, "Advances in fluid loss control additives for oil well cementing compositions," Oilfield Chemistry, vol. 24, no. 3, pp. 277-282, 2007.

[6] J. Plank, N. R. Lummer, and F. Dugonjić-Bilić, "Competitive adsorption between an AMPS $^{\circledR}$-based fluid loss polymer and Welan gum biopolymer in oil well cement," Journal of Applied Polymer Science, vol. 116, no. 5, pp. 2913-2919, 2010.

[7] J. Ma, H. Zheng, M. Tan et al., "Synthesis, characterization, and flocculation performance of anionic polyacrylamide P (AMAA-AMPS)," Journal of Applied Polymer Science, vol. 129, no. 4, pp. 1984-1991, 2013.

[8] C. Tiemeyer and J. Plank, "Synthesis, characterization, and working mechanism of a synthetic high temperature $\left(200^{\circ} \mathrm{C}\right)$ fluid loss polymer for oil well cementing containing allyloxy2-hydroxy propane sulfonic (AHPS) acid monomer," Journal of Applied Polymer Science, vol. 128, no. 1, pp. 851-860, 2013.

[9] Q. Xiao, W. F. Xiao, and X. X. Liu, "A novel cement fluid loss additive P1402," Advanced Materials Research, vol. 941-944, pp. 1203-1207, 2014.

[10] B. Peng, S. Peng, B. Long, Y. Miao, and W.-Y. Guo, "Properties of high-temperature-resistant drilling fluids incorporating acrylamide/(acrylic acid)/(2-acrylamido-2-methyl-1-propane sulfonic acid) terpolymer and aluminum citrate as filtration control agents," Journal of Vinyl and Additive Technology, vol. 16, no. 1, pp. 84-89, 2010.

[11] API, RP. 10B-2, Recommended Practice for Testing Well Cements, API, Washington, DC, USA, 2010.

[12] S. M. Yan, C. Sichuan, X. D. Wang, and F. Song, "Research of relationship between the fluid loss and the form of polymer in cement slurry," Journal of Southwest Petroleum Institute, vol. 28, pp. 99-102, 2006.

[13] S. Krishnamoorthi and R. P. Singh, "Synthesis, characterization, flocculation, and rheological characteristics of hydrolyzed and unhydrolyzed polyacrylamide-grafted poly(vinyl alcohol)," Journal of Applied Polymer Science, vol. 101, no. 4, pp. 2109-2122, 2006. 
[14] J. F. Zhang, J. J. Zhu, K. Dai, H. Tong, and T. Jiang, "Effect of temperature and additives on hydration products of Class $\mathrm{G}$ oil well cement," Journal of Daqing Petroleum Institute, vol. 28, pp. 94-97, 2004.

[15] D. C. Yuanguang Yang, "Study on recession of cement strength under high temperature," Oil Drilling \& Production Technology, vol. 5, pp. 33-39, 1992. 

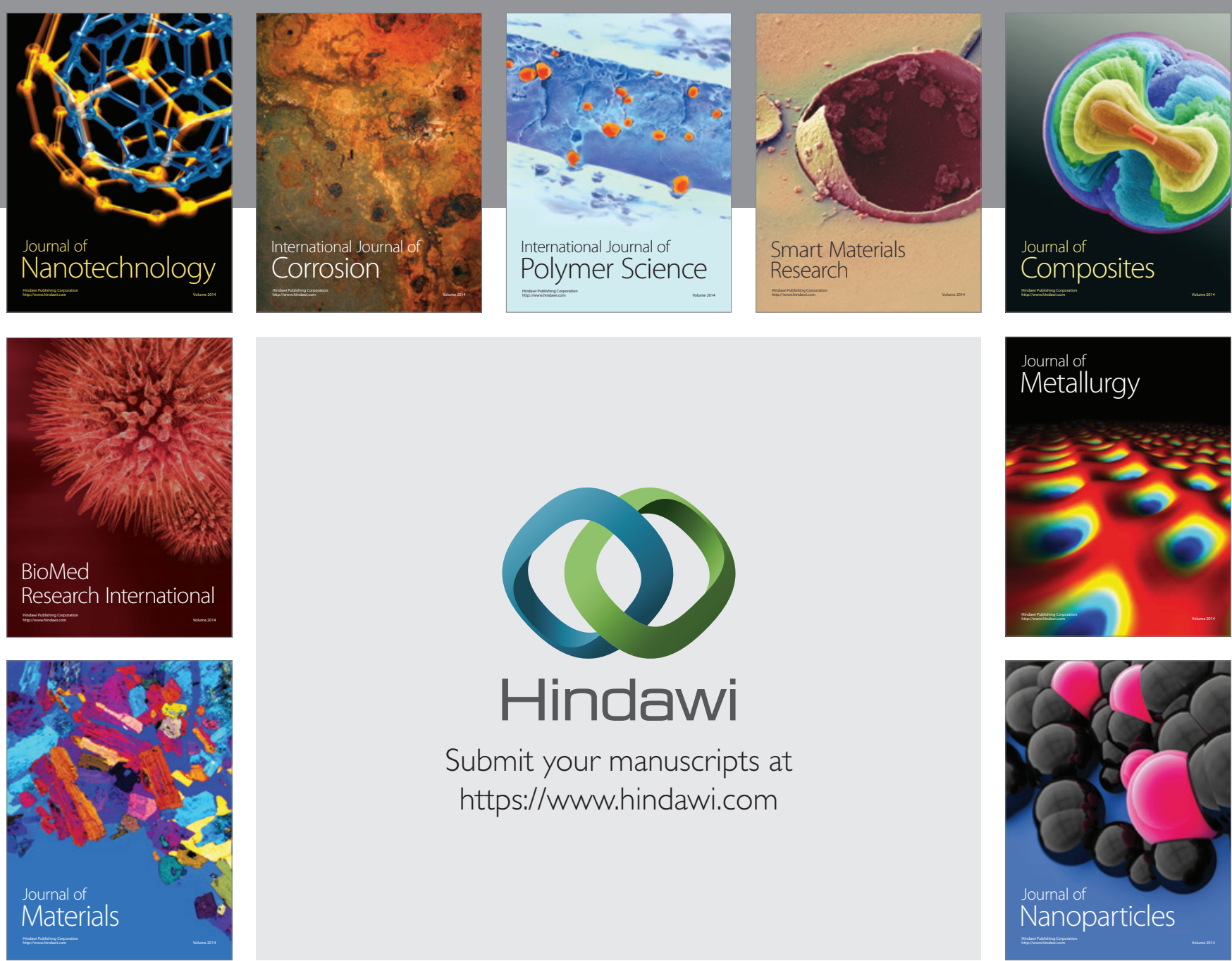

\section{Hindawi}

Submit your manuscripts at

https://www.hindawi.com

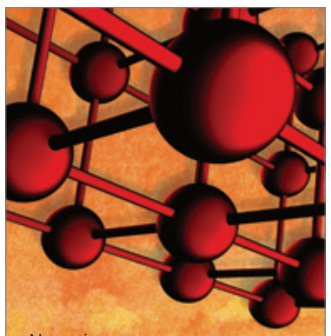

Materials Science and Engineering
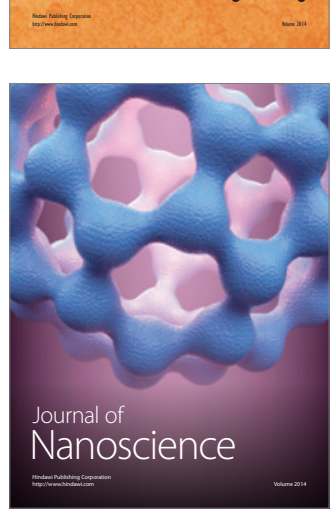
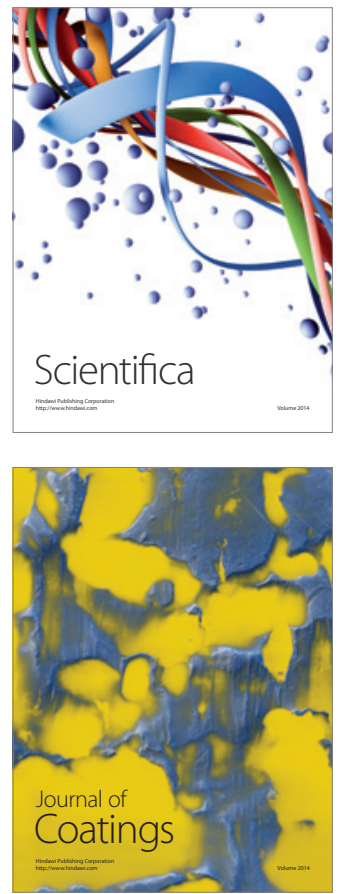
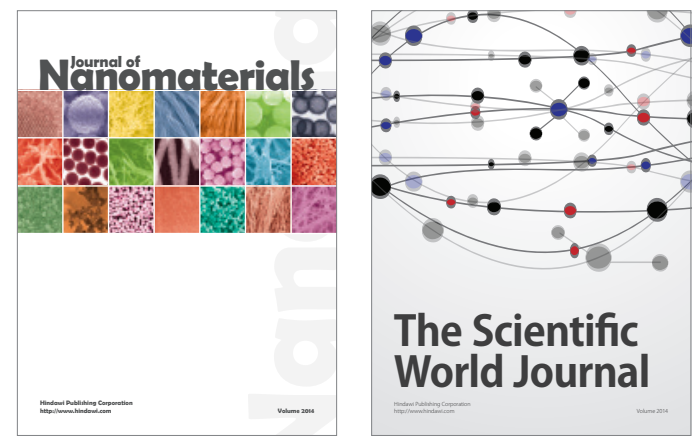

The Scientific World Journal
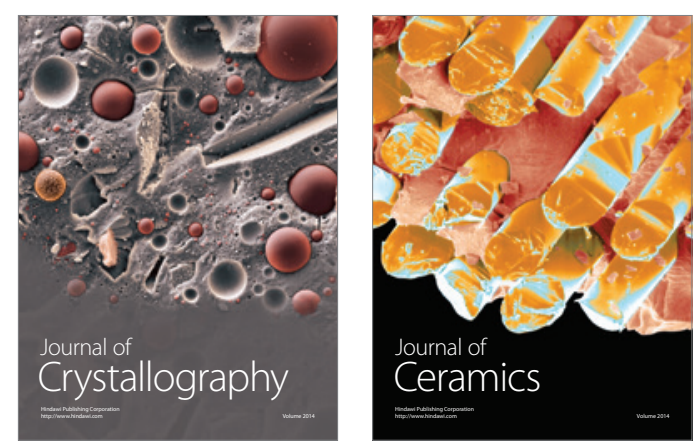
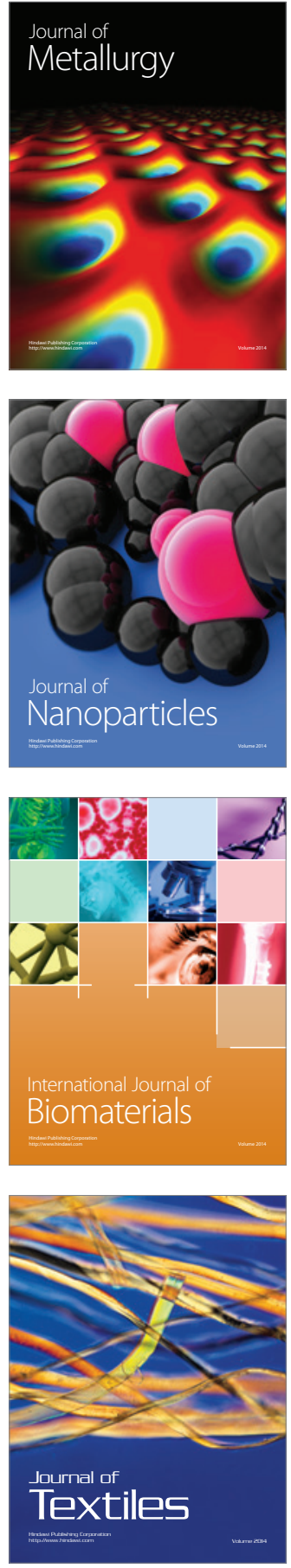